\title{
Characterization of Atmospheric Turbulence as a Function of Altitude
}

\author{
Suparnamaaya Prasad ${ }^{1}$ \\ York High School, Yorktown, VA,23692 \\ Marie L. Ivanco ${ }^{2}$, Thomas G. Ivanco ${ }^{3}$ and Ersin Ancel $^{4}$ \\ NASA Langley Research Center, Hampton, VA, 23681
}

\begin{abstract}
A novel radical shape change approach (Aerodynamically Actuated Radical Shape Change concept) was developed at NASA Langley Research Center. The radical shape change enables cruise at a lowered altitude of 15-25,000 feet and yields substantial performance and environmental benefits. This lowered altitude has however raised concerns in the community due to past experience with decreased ride quality in this altitude range. This paper describes the analysis performed by the team to address this concern. First, the team assessed and quantified turbulence occurrence as a function of altitude. Secondly, the team analyzed the effects of turbulence gust loads on the proposed concept when compared to conventional aircraft.
\end{abstract}

$\begin{array}{ll}\text { AARSC } & =\text { Nomenclature } \\ \text { AIDS } & =\text { Accident and Incident Data System } \\ \text { AIRMET } & =\text { Airmen's Meteorological Information } \\ C A T & =\text { Clear Air Turbulence } \\ F L & =\text { Flight Level } \\ G-A I R M E T & =\text { Graphical Airmen's Meteorological Information } \\ O M L & =\text { Outer Mold Line } \\ N A S A & =\text { National Aeronautics and Space Administration } \\ N O A A & =\text { National Oceanic and Atmospheric Administration }\end{array}$

\section{Introduction}

$\mathrm{R}$ ADICAL shape change has been used in aircraft design for many decades to enable radical regime changes within a mission profile. The F-111, F-14, B-1 bomber, MiG-2 and Mirage G are examples of production aircraft with successfully implemented radical shape change. The enabling technologies for these shape-change concepts often face difficult challenges such as weight penalties, complexity of design, the need for large acreage of flexible skin and a difficulty in maintaining a clean outer mold line (OML) for transonic/supersonic operation. ${ }^{1-3}$ These challenges increase maintenance requirements, cost and threaten performance and reliability. As a result, radical shape change is rarely beneficial to implement.

A team of engineers at NASA Langley Research Center developed a novel system concept, which addresses these drawbacks by enabling radical shape change using aerodynamic loads of a primary flight control rather than mechanical actuation. The Aerodynamically Actuated Radical Shape Change (AARSC) concept is the topic of a companion paper ${ }^{4}$ presented at this conference. This concept features telescoping wings driven by independently controlled dual winglets, which enable a clean cruise OML and alleviate the need for heavy actuators, drive trains, point loads or connecting structures found in systems with mechanical actuation. This novel radical shape change

\footnotetext{
${ }^{1}$ Student, York High School, Yorktown, VA 23692.

${ }^{2}$ Aerospace Engineer, Space Mission Analysis Branch, MS 462, Hampton, VA, 23681, AIAA member.

${ }^{3}$ Aerospace Engineer, Aeroelasticity Branch, MS 340, Hampton, VA 23681, AIAA senior member.

${ }^{4}$ Aerospace Engineer, Aeronautics Systems Analysis Branch, MS 442, Hampton, VA 23681, AIAA member.
}

American Institute of Aeronautics and Astronautics 
capability enables a new mission profile with a targeted lower cruise altitude of 15-25,000 feet. The increase in dynamic pressure realized at this lower cruise altitude warrants a radical change in the lifting surface of the aircraft in order to enable typical take-off and landing speeds, which can be accomplished with the AARSC concept with minimal penalties.

Lower altitude cruise has the potential to yield significant mission fuel savings by reducing fuel burn during climb and descent. Cruising at lower altitude also offers the benefit of an increased speed of sound, resulting in turn in a lower Mach number when traveling at a similar velocity than at higher cruise altitudes. Consequently, wave drag and wing-sweep requirements are decreased, structural weight can be reduced and aerodynamic efficiency improves. In addition, aircraft emissions have less environmental impact at lower altitude than the same level of emissions at higher altitude, adding environmental benefits to the economic and performance improvements.

Cruising at a lower altitude has however raised concerns in the community due to past experience with lowered ride quality in this altitude range. This concern warranted to examine to impact of cruise altitude on passenger comfort and safety, in order to determine the feasibility of the AARSC concept.

This paper describes the analysis performed by the team to assess and quantify turbulence occurrences as a function of altitude, as well as the effects of turbulence on the proposed concept when compared to conventional high speed aircraft.

\section{Background}

Atmospheric turbulence is characterized by chaotic changes in pressure and flow velocity ${ }^{5}$. Generally, the collision of air between the jet stream and slower moving air columns results in turbulence. Clear air turbulence (CAT) is one of the most common forms of turbulence and occurs due to certain weather conditions. CAT is invisible to radars and cannot be accurately forecasted using atmospheric models. Instead, reports from other aircraft are the main sources of information on regions of turbulence. Instances of turbulence are either passed on by other pilots directly or broadcast through air traffic control ${ }^{6}$.

Convective currents are another common source of turbulence and often appear at low altitudes. This type of turbulence is caused by the rising and falling of localized vertical air movements. Convective currents are most active on warm summer afternoons when winds are light due to uneven surface heating and can vary considerably within short distances. Similarly when cold air moves over a warm surface, it becomes unstable in lower levels, resulting in rough, choppy turbulence when flying in the cold air. This condition often occurs in any season after the passage of a cold front. Other indicators of possible convective turbulence are fair weather cumulus clouds. The cloud top usually marks the approximate upper limit of the convective current. A pilot can expect to encounter turbulence beneath or in the clouds, while above the clouds, air is generally smooth ${ }^{7}$.

The DC6 aircraft operated as a notable commercial airliner in the late 1940s up till the early 1960s in a service altitude range of 21,900 feet to 25,000 feet, an altitude range similar to the one targeted for the AARSC aircraft concept. A perception that ride quality was poor on this aircraft due to high levels of turbulence occurrences has remained in current years and the aeronautics community raised some concern when the AARSC concept was presented as an aircraft concept targeting a 15,000-25,000 feet cruise altitude range. The research team elected to address these concerns and performed an analysis to understand the impact of turbulence on the AARSC concept. It was determined that an aircraft's response to turbulence is determined by four factors: a) turbulence magnitude at flight level, b) the sensitivity of the aircraft to turbulence, c) the ability to avoid turbulent weather conditions and d) the active ride control system utilized by the aircraft. The analysis presented here focused on the first two factors: turbulence magnitude at flight level and the sensitivity of aircraft to turbulence. The other factors were not studied due to the fact that the ability to avoid weather systems today is not directly related to the aircraft design, and instead entails enhancement of current weather understanding, prediction capabilities, and onboard instrumentation and therefore does not impact the analysis of the AARSC aircraft concept. Additionally, the effects of a ride control system are difficult to quantify without access to the construction and flight testing of the ride control systems themselves and could therefore not be analyzed. The following sections will first present the method and obtained results of the statistical analysis of turbulence occurrence as a function of altitude. Then, the paper will discuss the analysis of wing loading and the effect of turbulence on the AARSC aircraft concept when compared to selected comparative production aircraft.

\section{Statistical Analysis of Turbulence Occurrence as a Function of Altitude}

Previous work has characterized CAT, however a literature review showed that while weather and turbulence data were available, an analysis of convective turbulence as a function of altitude was not ${ }^{8}$. To address this gap in the literature and to better comprehend turbulence occurences in the continental United States by altitude, the team 
performed an extensive statistical analysis of meteorological turbulence reports. In parallel, accident reports from the National Transportation and Safety Board were reviewed and analyzed to further characterize atmospheric turbulence as a function of altitude.

\title{
A. Analysis of Meteorological Turbulence Reports
}

The turbulence data used for the analysis was extracted from turbulence forecasts titled 'Airmen's Meteorological Information' (AIRMET) and graphical turbulence forecasts titled 'Graphical Airmen's Meteorological Information' (G-AIRMET). AIRMETs contain brief weather advisories to inform flight crews of weather conditions that may affect aircraft safety and ride comfort. The weather phenomena included in an AIRMET are turbulence, icing, sustained surface winds of 30 knots or greater and widespread restricted visibility. Turbulence related AIRMETS are identified by the handle 'AIRMET TANGO' and state a range of flight levels containing active turbulence. AIRMETs used for this analysis were accessed through the data archives from the National Oceanic and Atmospheric Administration (NOAA). The team requested AIRMET archives for selected twenty-four hour periods in 2016. Data was requested for the first, second, eighth, ninth, fifteenth, sixteenth, twentysecond, and twenty-third day of each month, for a total of ninety-six days in the calendar year. Two days were requested for each week of each month in an effort to capture a global representation of weather events throughout the calendar year. Due to the size of the files and the request process to access the archives, it would have been unpractical to request more data than the chosen data set.

The data included in a typical AIRMET TANGO report is not listed in plain English and uses unique acronyms and formatting styles. Figure 1 shows an example of an AIRMET report that contains turbulence data. Flights levels (FL) at which turbulence occur are listed in three different fashions: TURB BLW 040, TURB FL280-380, or TURB BLW 5000FT. While altitude is the vertical distance of an object measured from mean sea level, the flight level is a surface of constant atmosphere pressure which is related to a specific pressure datum, $1013.2 \mathrm{hPa}$, and is separated from other such surfaces by specific pressure intervals ${ }^{9}$. In this analysis, flight levels were assumed to equal the altitudes of the observed turbulences. Conversion from a given flight level to an altitude measured in feet was accomplished by multiplying the flight level by one hundred. For example, FL100 is equivalent to ten thousand feet in altitude.

\author{
Type: AIRMET Hazard: TURB \\ Day: January 22, 2016 \\ WAUS44 KKCI 220528 AAA \\ WA4T \\ DFWT WA 220528 AMD \\ AIRMET TANGO UPDT 1 FOR TURB STG WNDS AND LLWS VALID UNTIL 220900 \\ - \\ AIRMET TURB...OK TX AR TN LA MS AL AND CSTL WTRS \\ FROM OSW TO RZC TO ARG TO DYR TO HMV TO GQO TO LGC TO 60SSW LEV \\ TO 120SSW LCH T0 80E BRO TO 90W BR0 TO DLF TO 80 S MRF T0 70E ELP \\ TO INK TO 30ESE TBE TO 50W LBL TO OSW \\ MOD TURB BTN FL180 AND FL390. CONDS CONTG BYD 09Z THRU $15 Z$.
}

Figure 1. AIRMET Report Example.

The archived data had to be requested from NOAA for two days at a time. The data was received in a folder containing one hundred to two hundred data files. The data files were not solely focused on atmospheric turbulence data; many files contained various weather phenomena data, such as air pressure readings, thunderstorm warnings, etc. In order to determine those that contained turbulence related AIRMETs, a Python script was written to conduct 
a search for the keywords 'AIRMET TURB' in each file. This code allowed to reduce the data set to only files that contained relevant turbulence data, approximately ten to twenty per each selected day.

A MATLAB code was then used to parse through the files and extract the specific flight levels at which turbulence occurred. The extracted ranges were then exported to an output file for each day. A final Python code was developed to read each output file. The code first creates bins in 1000 feet increments, ranging from 0 to 50,000 feet and initializes a counter in each altitude bin. The code then parses through the output file and each time a turbulence occurrence was registered to occur within any of the specified altitude sectors, $a+1$ would be added to the appropriate altitude bin. For example, a turbulence range FL180-FL190 would increase the altitude bins concerning the altitudes of 18,000 feet and 19,000 feet by 1 . If a given turbulence was below a certain altitude, the code would add 1 to all bins below the specified altitude.

A histogram of the number of turbulence occurrences as a function of altitude is shown in Fig. 2. It can be observed that less turbulence is experienced in the altitude range targeted by the AARSC concept than in the altitude range most used by high speed commercial transport aircraft.

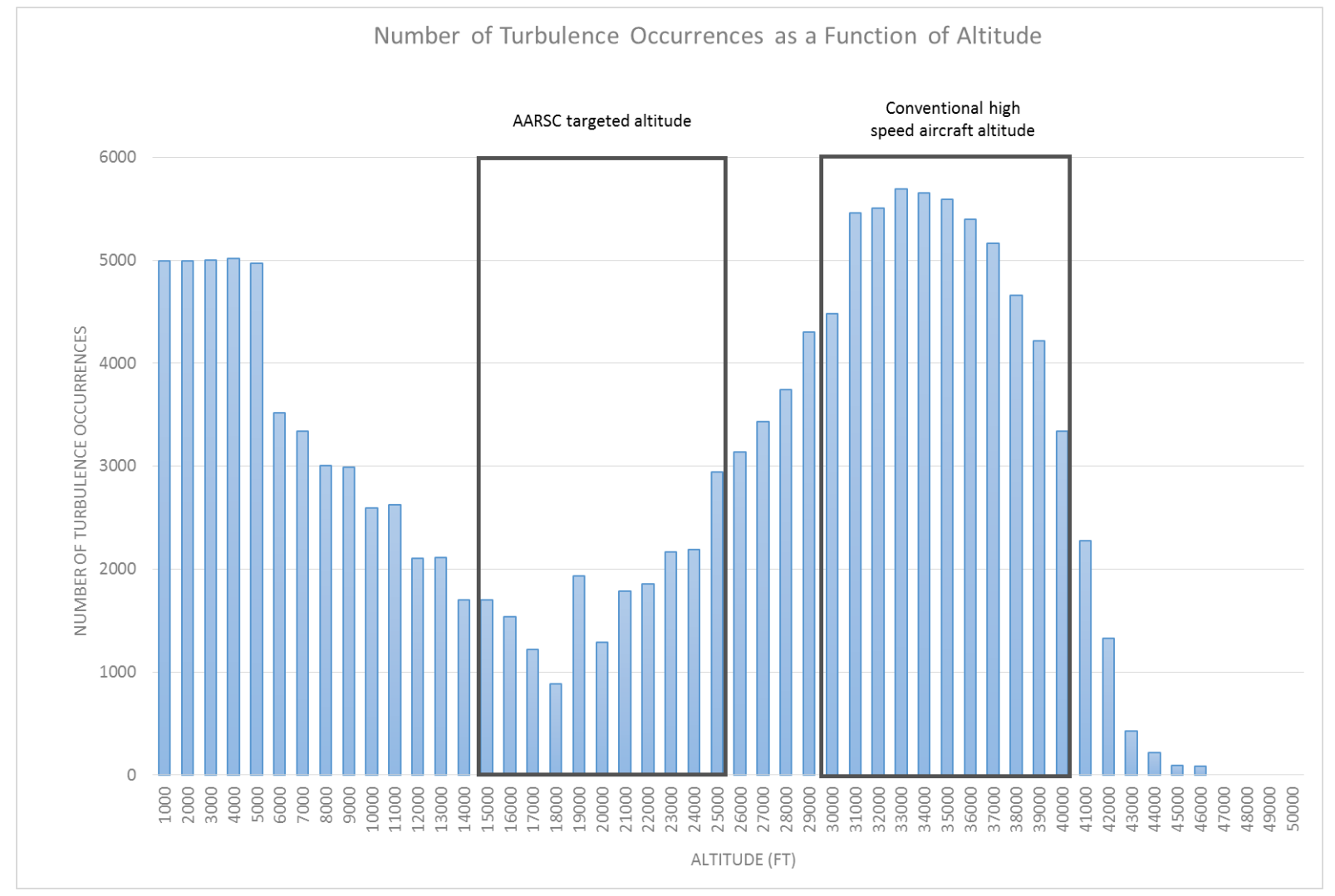

Figure 2. Number of turbulence occurrences as a function of altitude.

The data dispersion in altitude increments of 5,000 feet is shown in Figure 3. The small size of the boxes on the plot reflects a low variability in the data for the second and third quartiles. The 15,000 to 20,000 feet range shows some of the greatest consistency in the data for these quartiles. More data dispersion can be observed for the fourth quartile for all of the considered ranges, highlighting that a significantly greater number of turbulence occurrences is occasionally experienced in each altitude range throughout the year. The medians shown on the plot reflect the trend already observed in the histogram of Fig. 2. 


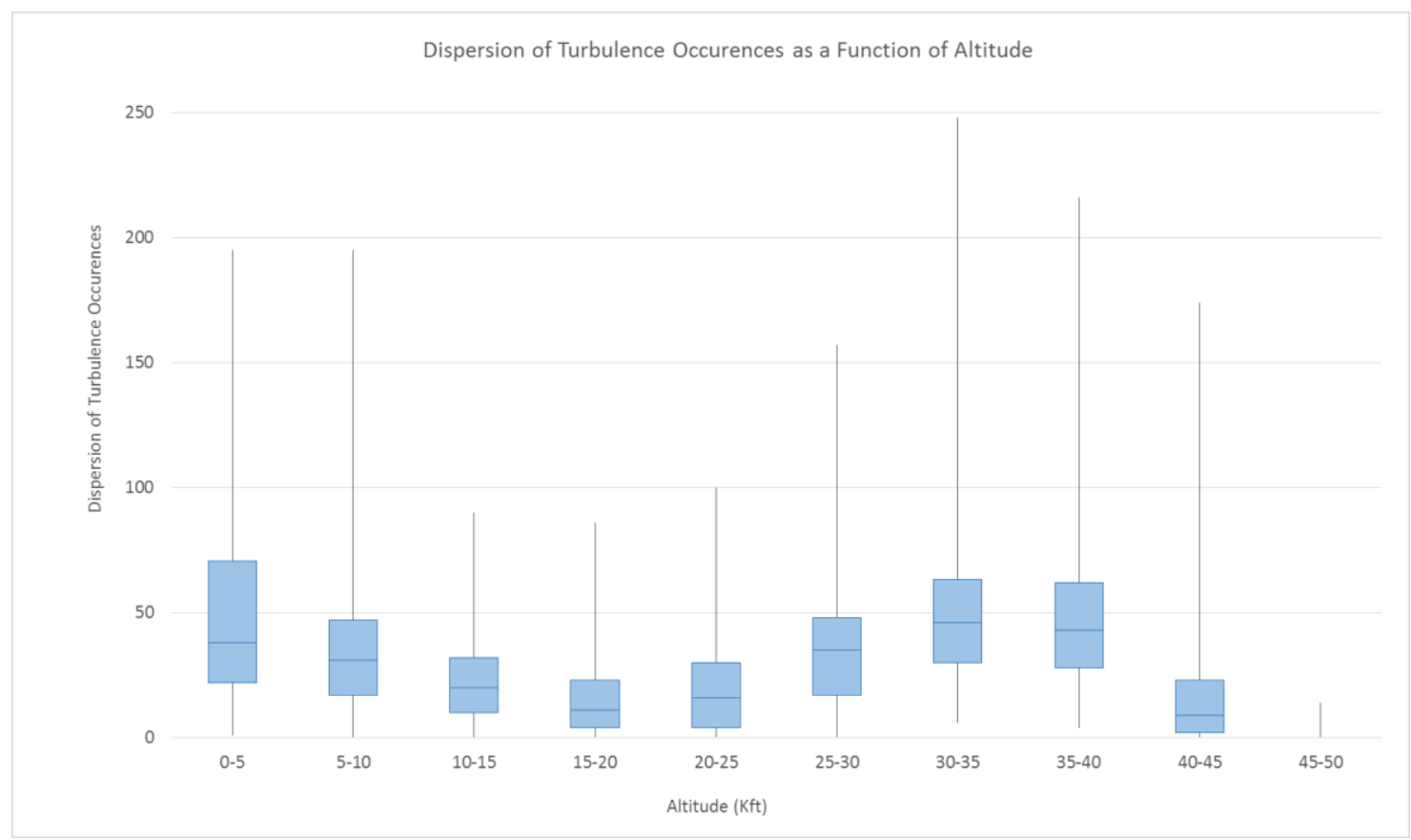

Figure 3. Dispersion of turbulence occurences as a function of altitude.

Figure 4 shows the number of turbulence occurrences in altitude ranges of 5,000 feet increments for each season. The overall trend shown in the histogram of Fig. 2 is observed for each season in Fig. 4, confirming that less turbulence occurrences are consistently observed throughout the year in the 15,000 feet to 25,000 feet range than in the 30,000 feet to 40,000 feet range. It can be of interest to note that less turbulence events were recorded in the summer time and that more events were recorded in the fall.

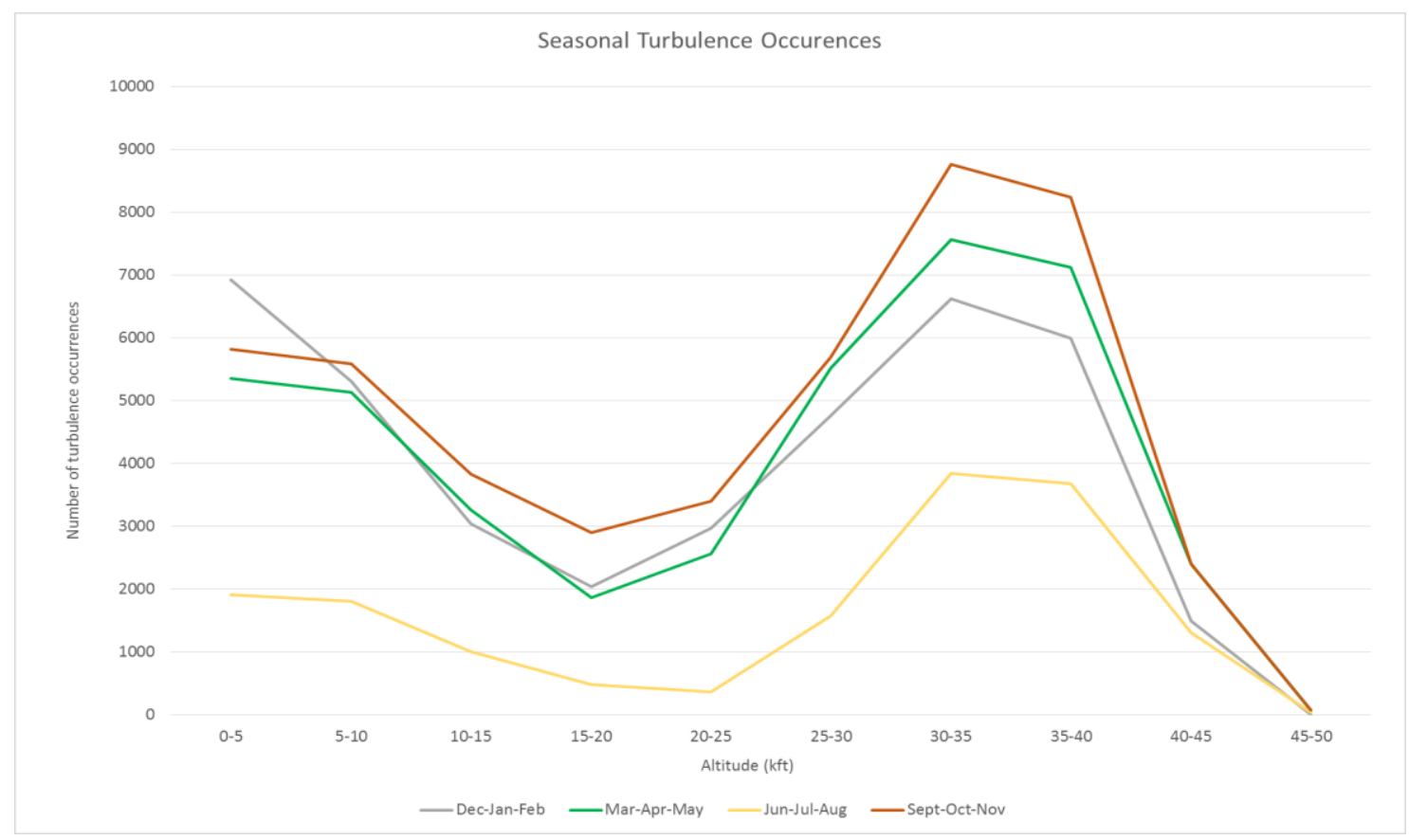

Figure 4. Seasonal Turbulence Occurences

American Institute of Aeronautics and Astronautics 


\section{B. Accident Data Analysis}

Besides the meteological turbulence reports, turbulence related aircraft accident reports were also considered as a data source in characterizing atmospheric turbulence with respect to altitude. A copy of the FAA Accident and Incident Data System (AIDS) data is periodically updated and further categorized by the Aeronautics and Systems Analysis Branch (ASAB) at LaRC. A subset of this dataset was examined to evaluate if an excess of accidents occur in a particular altitude interval. The dataset is comprised of turbulence related accidents within FAR Parts 91, 135, and 121, spanning from 1995 to 2014. In addition to CAT, the turbulence subcategories considered include turbulence caused by thunderstorms (or convective turbulence) as well as turbulence occurring in clouds. The resulting dataset contains 221 data points, where 212 entries contain distinct altitude information. The accidents were then further categorized to reflect aircraft type (large jets, small jets, and turboprops) as well as the altitude where the turbulence was encountered (above 27,000 feet, between 20,000 and 27,000 feet and below 20,000 feet). Further information on both aircraft and turbulence categories can be obtained in Ref. 10.

The preliminary analysis of the data indicated that in the large jet category aircraft, $47 \%$ of the turbulence was encountered above 27,000 feet, $19 \%$ of the turbulence encountered took place between 20,000 to 27,000 feet, and finally $32 \%$ of turbulence events occurred in altitudes at or below 20,000 feet (Fig. 5). On the other hand, small jet category aircraft turbulence encounters were equally likely at below 20,000 feet and above 27,000 feet, with 36\% each. In the same category, the turbulence occurrence between 20,000 and 27,000 feet represented about $25 \%$ of all small jet turbulence accidents. Additionally, all turboprop aircraft turbulence encounters took place at 20,000 feet or below. Finally, independent from aircraft type, $41 \%$ of all turbulence events took place above 27,000 feet, 38\% of them were encountered at or below 20,000 feet whereas the remaining $17 \%$ of them occurred at altitudes between 20,000 and 27,000 feet. The preliminary data indicate that, overall, turbulence encounters were least likely in the 20,000 to 27,000 feet range, in which the conceptual AARSC aircraft is proposed to operate. As promising as the initial results are, it is important to note that the accident data mirrors operational data. Consequently, the results are likely skewed towards cruise altitudes (i.e. the aircraft is expected to experience turbulence at the cruise altitude where the majority of the flight is spent). For this reason, further analysis of the data in an effort to normalize for traffic density in various altitude levels will be necessary in the future.

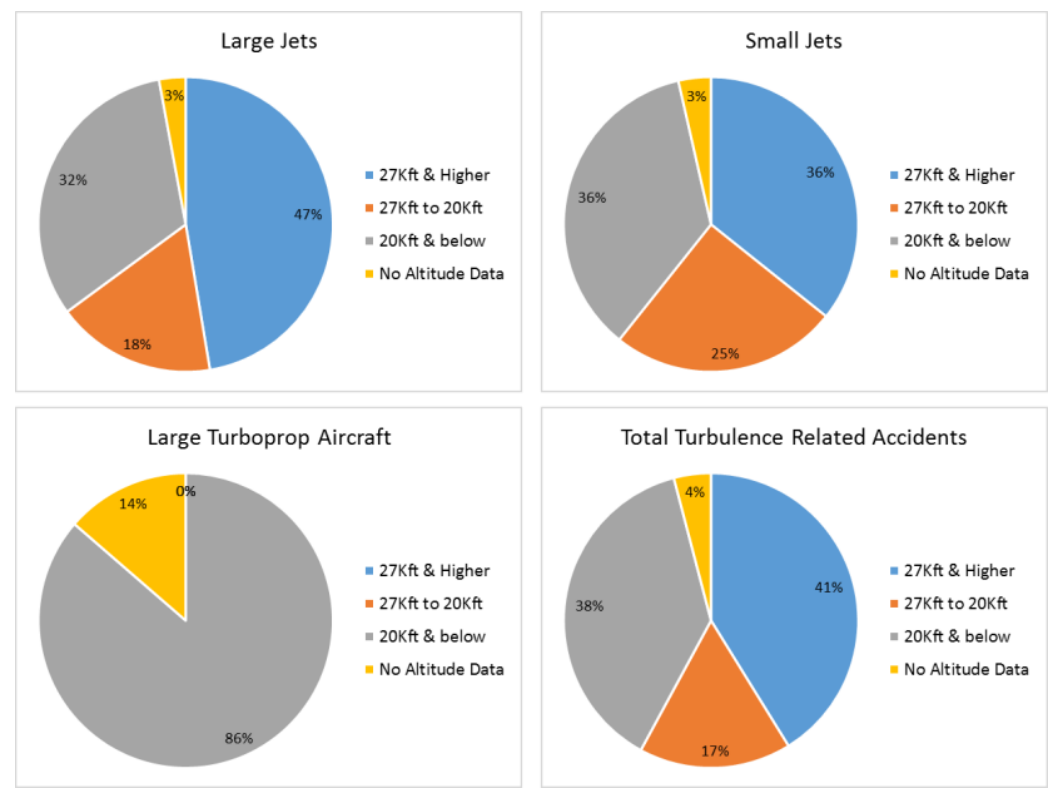

Figure 5. Turbulence related accidents by altitude and aircraft type

\section{Wing Loading and Turbulence Effects}

The impact of turbulence on the AARSC concept in the 15,000-25,000 feet altitude range is a factor of turbulence occurrence in this targeted range, but is also a factor of the effects of turbulence that do occur on this specific aircraft concept and its properties. NACA report $1206^{11}$ provides equations to calculate the acceleration of an aircraft for a given turbulence gust load. The equations show that airplane weight, wing area, wing span, the wing 
lift-curve slope, air density, airspeed and maximum gust velocity are variables that influence the acceleration of the aircraft due to gust loads. Using these equqations, accelerations for a unit gust load were calculated for the DC6 aircraft flying at 20,000 feet, the AARSC concept flying at 20,000 feet and for a Boeing 737-800 aircraft flying at 20,000 feet and 35,000 feet. The 737-800 was selected as the baseline as it is a good representation of the current state of the art for passenger airliners with similar mission range and passenger capacity than the AARSC concept. Table 1 shows the ratios of the computed accelerations for the various case studies and Fig. 6 offers a visualization of the results.

Table 1. Ratio of accelerations due to a unit gust load

\begin{tabular}{|c|c|c|c|c|}
\hline & $\begin{array}{c}\text { DC6 } \\
\text { DC, } 000 \mathrm{ft}\end{array}$ & $\begin{array}{c}\text { AARSC } \\
20,000 \mathrm{ft}\end{array}$ & $\begin{array}{c}737-800 \\
20,000 \mathrm{ft}\end{array}$ & $\begin{array}{c}737-800 \\
35,000 \mathrm{ft}\end{array}$ \\
\hline $\begin{array}{c}\text { DC,000 ft } \\
\text { AARSC }\end{array}$ & 1.00 & 3.29 & 1.96 & 3.29 \\
\hline $20,000 \mathrm{ft}$ & 0.30 & 1.00 & 0.60 & 1.00 \\
\hline $\begin{array}{c}737-800 \\
20,000 \mathrm{ft}\end{array}$ & 0.51 & 1.68 & 1.00 & 1.68 \\
\hline $\begin{array}{c}737-800 \\
35,000 \mathrm{ft}\end{array}$ & 0.30 & 1.00 & 0.60 & 1.00 \\
\hline
\end{tabular}

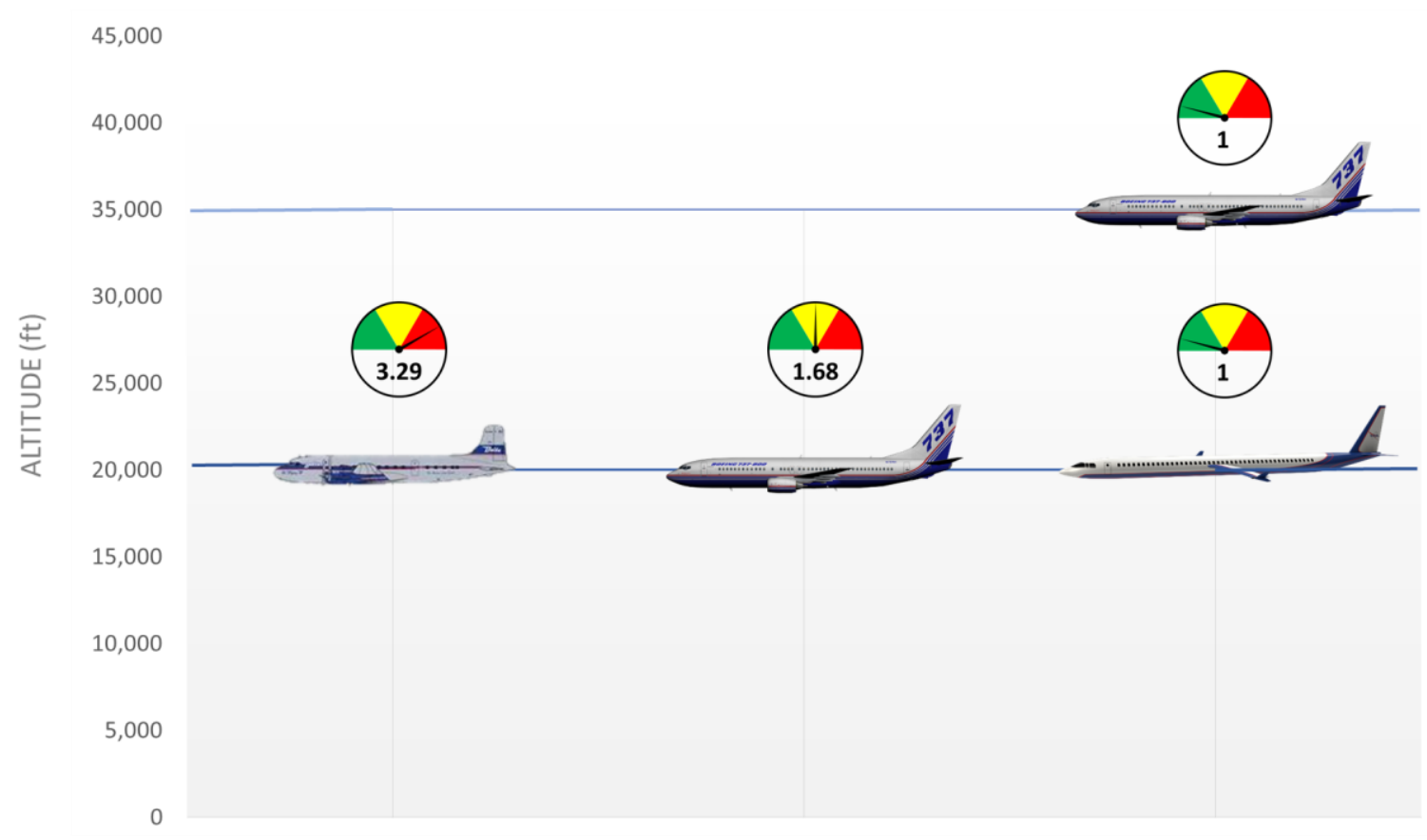

Figure 6. Visualization of the ratios of accelerations due to a unit gust load.

The results show that the AARSC concept would experience a similar acceleration due to a unit gust load when flying at 20,000 feet than the baseline aircraft flying at 35,000 feet, making the ride quality in the AARSC aircraft comparable to what passengers are currenlty experiencing on a Boeing 737-800 at its typical cruise altitude. The AARSC concept would experience less acceleration than both the baseline aircraft and the DC6 flying at 20,000 feet for a similar unit gust load. The acceleration calculated for the DC6 is greater by more than a factor of three than the acceleration calculated for the AARSC concept. 


\section{Conclusion}

This study concluded that the probability of moderate to severe turbulence encounters is lower at cruise altitudes of 15,000 feet to 25,000 feet by comparison to typical cruise altitudes of 30,000 feet to 40,000 feet for conventional high speed transport aircraft. The data also show that the altitude range targeted by the AARSC concept had fewer turbulence occurrences in 2016 than most other altitudes. The data had little variability in the second and third quartiles when sorted in 5,000 feet altitude bins, but some variability could be observed in the fourth quartile, reflecting occasional peaks in turbulence events. The maximum number of turbulence occurences was however closer to the median in the 15,000 to 25,000 feet range than in the 30,000 to 40,000 feet range. The overall trend of turbulence occurrences as a function of altitude remains the same throughout the seasons, consistenly showing more favorable conditions in the 15,000 feet to 25,000 feet range. The accident data analysis confirmed the findings obtained through the analysis of the AIRMET data. Lastly, the response of the AARSC concept to a unit gust is several factors less than the response of conventional aircraft, such as the DC-6, at the same altitude due to design parameters that include wing loading, cruise velocity, and gross weight. The findings of this analysis enable to conclude that targeting a lower altitude for the AARSC concept is feasible in terms of ride quality and passenger comfort.

\section{References}

${ }^{1}$ Ivanco, T. G.; Scott, R. C.; Love, M. H.; Zink, S.; and Weisshaar, T. A., "Validation of the Lockheed Martin Morphing Concept with Wind Tunnel Testing," AIAA Structural Dynamics and Materials Conference, Honolulu, HI, AIAA 2007-2235, April 2007.

${ }^{2}$ Love, M. H; Zink, S.; Bye, D. R.; Rizk, S. N.; Stroud, R. L.; and White, D. W., "Demonstration of Morphing Technology through Ground and Wind Tunnel Tests," AIAA Structural Dynamics and Materials Conference, Honolulu, HI, AIAA 2007-1729, April 2007.

${ }^{3}$ Weisshaar, T. A.; "Morphing Aircraft Systems: Historical Perspectives and Future Challenges," Journal of Aircraft, Vol. 50, No. 2, 2013, pp. 337-353.

${ }^{4}$ Ivanco, T., Ivanco, M., Ancel, E., Grubb, A., Prasad, S., Aerodynamically-Actuated Radical Shape Change, submitted for approval to AIAA Aviation 2017, to be published.

${ }^{5}$ Tennekes, H.; Lumley, J.L., A First Course in Turbulence, MIT Press, 1972.

${ }^{6}$ Hicks, J., Katz, I., Landry, C., and Hardy, K., Clear-Air Turbulence: Simultaneous Observations by Radar and Aircraft, Science 18 August 1967: Vol. 157. no. 3790, pp. 808-809.

${ }^{7}$ Aviation Weather. (n.d.). Retrieved from https://www.aviationweather.ws/044_Convective Currents.php.

${ }^{8}$ Ashburn, E., Waco, D., and Mitchel, F., Development of High Altitude Clear Air Turbulence Models, LockheedCalifornia Company AD866372, 1972.

${ }^{9}$ Altitude, Flight Level and Height. (2011, October 12). Retrieved from https://www.skybrary.aero/index.php/Altitude,_Flight_Level_and_Height.

${ }^{10}$ Evans, J. K., "An Updated Examination of Aviation Accidents Associated with Turbulence, Wind Shear and Thunderstorm," Analytical Mechanics Associates, Inc. AMA Report Number 14-14, Hampton VA, Dec. 2014.

${ }^{11}$ Pratt, K., Walker, W., A revised gust-load formula and a re-evaluation of V-G data taken on civil transport airplanes from 1930 to 1950, NACA Report 1206. 